\title{
Mobile Technology for increasing Postpartum Family Planning Acceptability: The Development of a Mobile- based (mHealth) Intervention through a Dedicated Counselor-A Pilot Innovative Study conducted in a Tertiary Teaching Hospital of Agra, Uttar Pradesh, India
}

${ }^{1}$ Nidhi Gupta, ${ }^{2}$ Akanksha Gupta, ${ }^{3}$ Sunita Bhagia, ${ }^{4}$ Saroj Singh

\begin{abstract}
Objective: This prospective study was undertaken to increase postpartum family planning (PPFP) acceptance among urban slum dwellers in Agra city by initiating postpartum (PP) women tracking through free phone calls and effective counseling by counselor, wherein the potential clients can be followed up and called back to the health facility for postnatal care (PNC) checkups and immunization of the newborn and helped in making an informed choice of the PPFP method best suitable to them.
\end{abstract}

Materials and methods: A thorough analysis of PPFP methods at the PP center at S.N. Medical College, Agra, India, showed that the acceptance of PPFP methods was low. To boost up the PPFP program, an innovation of mobile tracking of PP women was done by a counselor. Every day the experienced counselor counseled all women in early labor in clean labour room (CLR) and recently delivered clients in PNC ward and postoperative ward on PPFP methods and services. Some of them adopted immediate PP intrauterine contraceptive device (PPIUCD) or ligation, while others were tracked by the counselor through their mobile numbers for the next 2 months. The counselor makes the following free phone calls to the potential clients:

First call within 3 to 7 days of delivery

Second call in 20 to 42 days of delivery

Third call in 42 to 60 days of delivery

This tracking was started in 2013 and completed in 2016. The results of acceptability and acceptance have been compiled.

\section{Results:}

- This pilot study has shown very promising results. Hence, according to this study, the effective PPFP has increased to $29.7 \%$, which was initially $4.9 \%$.

- Also, PPFP acceptance has increased from 6\% in 2012 to $73 \%$ in 2015 , including all methods [condom and oral contraceptive pill (OCP)/progestin-only pill (POP) also].

The PP women who did not accept any method were referred to their respective nongovernmental organization (NGO) and

\footnotetext{
${ }^{1}$ Associate Professor, ${ }^{2}$ Assistant Professor, ${ }^{3}$ Technical Advisor ${ }^{4}$ Professor

1,2,4 Department of Obstetrics and Gynecology, Sarojini Naidu Medical College, Agra, Uttar Pradesh, India

${ }^{3}$ Department of Obstetrics and Gynecology, UHI Agra, Uttar Pradesh, India

Corresponding Author: Akanksha Gupta, Assistant Professor Department of Obstetrics and Gynecology, Sarojini Naidu Medical College, Agra, Uttar Pradesh, India, e-mail: akankshabhigupta@ gmail.com
}

they were then counseled by them and the acceptance further increased by another $5 \%$.

Conclusion: The tracking of PP women through mobile communication by the counselor in Agra city since last 48 months of implementation seems to be successful. It is going in the right direction. Linking up the recently delivered clients by the respective NGO to the nearby health facility for PPFP methods and services is playing an important role and will definitely improve with time and intensive efforts.

Keywords: Counselor mHealth, Mobile based technology, Postpartum family planning.

How to cite this article: Gupta N, Gupta A, Bhagia S, Singh S. Mobile Technology for increasing Postpartum Family Planning Acceptability: The Development of a Mobile-based (mHealth) Intervention through a Dedicated Counselor-A Pilot Innovative Study conducted in a Tertiary Teaching Hospital of Agra, Uttar Pradesh, India. J South Asian Feder Obst Gynae 2018;10(1):74-80.

Source of support: Nil

Conflict of interest: None

Date of received: 15 January 2018

Date of acceptance: 25 February 2018

Date of publication: May 2018

\section{INTRODUCTION}

About 15 years earlier, PPFP was practically nil. Delivery was the main focus and that too was carried out in the homes by untrained personnel and hence maternal mortality rate and infant mortality rate were very high.

With the passage of time, literacy, education, empowerment of women, the trend has changed.

Integrating FP in the PP period has been one of the important strategies to meet the unmet need of FP of the target group, as women are vulnerable and receptive to FP advice and readily accept a method in the PP period.

It has been observed that after going home, the women forget the trauma of pregnancy and labor pains. Thereafter, FP is not their priority and they keep postponing it. Finally, they land up with an unwanted pregnancy and get an abortion done, which affects their physical and mental health as well. Using FP to space births at least 36 months apart can avert $30 \%$ of maternal deaths and $10 \%$ of child deaths. ${ }^{1,2}$ 
In India, however, only $26 \%$ of PP women are using contraceptives $^{3}$ and more than $60 \%$ of births follow an interval of less than 36 months. ${ }^{4}$ Sixty-five percent of PP women in India have an unmet need for contraception to delay or limit future pregnancies. ${ }^{3}$ This is similar to the levels of unmet need across 27 countries. ${ }^{5}$ Sterilization has remained the leading method of contraception in India, accounting for $40 \%$ of FP users, ${ }^{4,6}$ but it does not address women's needs for healthy birth spacing.

The PPIUCD-long-acting, reversible contraceptiveoffers a safe, effective, and convenient alternative. ${ }^{7}$ Also, it has been found to be acceptable among Indian women. ${ }^{8,9}$

In the last decade, more and more women chose to give birth in health institutions. Proportion of deliveries taking place at health facilities increased from $41 \%$ during 2005 to $2006^{4}$ to $86.9 \%$ at present. ${ }^{10}$ This preference has emerged due to the government's flagship programJanani Suraksha Yojana (JSY), a conditional cash transfer scheme for promoting institutional deliveries. It is a part of government's efforts to reduce maternal and neonatal mortality under the National Health Mission. ${ }^{11}$

Given high unmet need for birth spacing and the rise in institutional deliveries, the Government of India with technical support from NGOs like Urban Health Initiative), Jhpiego, and others, has been working to reinvigorate and scale up the use of PPFP, with a focused effort on expanding the capacity to provide PPIUCD services. Appropriate provision of PPFP services includes antenatal counseling, peripartum support for initiating a method, and PP guidance to successfully continue use.

Institutional deliveries create a unique opportunity to offer methods of contraception to women immediately following their childbirth. Delaying acceptance until later is less effective because most clients tend not to return to facilities for FP services. ${ }^{12}$ Cost is not a barrier for women because FP services in India are provided free of cost at government health facilities.

With this concept in mind, PPFP especially PPIUCD was initiated and boosted in Agra in the year 2011, but the acceptance was very poor.

Acceptance of individual PPFP method by women delivered at S.N. Medical College, Agra, 2012 (Table 1).

According to 2012 data, $95 \%$ of women delivered were not accepting any contraceptive method. The idea about

Table 1: Acceptance of individual method by women delivered at S.N. Medical College, Agra

\begin{tabular}{ll}
\hline PP contraceptive method & 2012 \\
\hline PPIUCD & $36(1.72 \%)$ \\
Female sterilization & $54(2.58 \%)$ \\
Lactational amenorrhea method & $2(0.09 \%)$ \\
Oral contraceptive pill/minipill & $2(0.09 \%)$ \\
\hline
\end{tabular}

tracking of the PP women through phone calls originated after observation that PPFP was very low in urban poor community, and in this modern era of 21st century, many of the poor possessed mobile phones.

Mobile phone-based interventions (mHealth) refer to the use of mobile technologies for health. ${ }^{12}$ mHealth interventions can utilize different modes of communication; e.g., text, voice or video messages, and smartphone applications that may involve one-way or two-way communication. ${ }^{13}$ These services are cost-effective and has the potential to reach youth, urban slums, and rural population where geographical distances or daily wages earning loss restrict access to in-person services. ${ }^{14}$

Although a number of $\mathrm{mHealth}$ contraceptive services have been initiated in a number of countries ${ }^{15-21}$ in lowincome settings, till date these are lacking in India, so this is a pilot innovative study conducted to see the impact of mHealth on acceptance of PPFP services.

Hence it was thought of piloting this idea of PP women tracking through mobile communication by the counselor to improve and increase PPFP acceptance among the urban poor slum community.

A positive response to free phone calls made by the experienced counselor, calling up recently delivered clients, was expected through this activity, as the clients will get satisfied after speaking to the counselor who will help in solving their myths and queries related to PPFP and also help in readily adopting a method best suited to them. Hence, it was discussed and decided to initiate PP women tracking through mobile communication actively in Agra city.

The PPFP methods offered to the potential clients are:

- Intrauterine contraceptive device

- Female sterilization

- Male sterilization

- Depot medroxyprogesterone acetate (DMPA)

- Condom

- Lactational amenorrhea method (LAM)

- Progestin-only pill/oral contraceptive pill.

Postpartum period includes:

Immediate-within 48 hours of delivery

Early PP period-within 7 days of delivery

Extended PP period - 6 weeks to 1 year after delivery

For our study, we counseled the PP women for up to 2 months only in the extended PP period and later they were tracked and counseled by the NGOs working in the urban slums.

In the immediate PP period, a couple can adopt:

- Intrauterine contraceptive device

- Female sterilization

- Male sterilization

- Condom

- Lactational amenorrhea method 
In the early PP period:

- Female sterilization

- Male sterilization

- Condom

- Lactational amenorrhea method. Extended PP period:

All the methods can be adopted by the target couple according to their choice and contraceptive needs.

- Oral contraceptive pill can only be started at 6 months PP period

- Depot medroxyprogesterone acetate at 6 weeks PP

- Rest of the methods can be taken in the immediate and early PP period.

\section{Advantages of PPFP}

- During the PP period, a woman is very receptive to accept a FP method for spacing or limiting her family size as she has gone through the trauma of pregnancy and delivery and does not want the next pregnancy very early

- The return of fertility is as early as 6 weeks after delivery. So if a woman takes a FP method in the immediate or early PP period, she will be protected from the trauma of unwanted pregnancy and anemia as well and the fear of unprotected sex and later on getting an abortion done

- In the extended PP period, if a woman adopts a FP method of her choice and practices healthy spacing of pregnancy, she can pay more attention to her own health, care for the new born in a better way, breastfeeding, timely immunization, complimentary feeding, health, and hygiene

- Overall health of the family and family welfare will improve

- Maternal morbidity and mortality will reduce

- Infant morbidity and mortality will reduce

- The PPFP counseling starts as early as in III trimester (7-9 months) of pregnancy in the antenatal period

- When the pregnant woman comes for checkups, she can be told about the advantages of institutional delivery, safe motherhood, breastfeeding, JSY government scheme and offered all PPFP methods and services to make an informed choice and guided correctly by the counselors and service providers

- She has ample time to go back and think over and decide for a PPFP method after discussion with her husband and mother-in-law

- The woman during the counseling session in antenatal care (ANC) period can be told about the various service delivery points, and that if she adopts the method in the immediate or early PP period, it will be economical as the cost will be included with the delivery charges and she will not have to pay extra for
PPFP in the Private Health Facility, but if she comes later, she will have to spend separately for adopting a FP method.

\section{Goal}

This prospective study was undertaken to increase PPFP acceptance among urban slum dwellers catered by PP center, S.N. Medical College, Agra, India, by initiating PP women tracking through free phone calls and effective counseling by counselor, wherein the potential clients can be followed up and called back to the health facility for PNC checkup and immunization of the new born and helped in making an informed choice of the PPFP method best suitable to them.

\section{Objectives}

After attending the phone calls made by the counselor, the recently delivered potential client of S.N. Medical College and hospital will be able to understand the importance of PPFP methods and services and their importance in improving maternal and child health. It will help in better understanding of the client about PNC checkup and new born care and timely immunization of 0 to 1 year. This will build up confidence in the counselor who is guiding them and helping them at each service level (PNC checkup, new born care and checkup, immunization point).

The recently delivered women will take her help in choosing a FP method according to their contraceptive needs and in availing quality PPFP services too.

\section{MATERIALS AND METHODS}

A thorough analysis of PPFP methods at the PP center at SN Medical College showed that the acceptance of PPFP methods was low.

To boost up the PPFP program, an innovation of mobile tracking of PP women was done by a counselor.

Every day the experienced counselor counseled all women in early labor in CLR and recently delivered clients in PNC ward and postoperative ward on PPFP methods and services.

Some of them adopt immediate PPIUCD or ligation, while others are tracked by the counselor through their mobile numbers for the next 2 months.

She asks them on phone call about:

- Wellbeing of the mother and baby

- Gives information on LAM and optimal breastfeeding

- Tells them about the immunization schedule of 0 to 1-year-old baby

- Talks about PPFP methods and services available

- Solves any queries and problems related to maternal and child health 
Mobile Technology for Increasing PPFP Acceptability

\begin{tabular}{|c|c|c|}
\hline $\begin{array}{l}\text { Postpartum family } \\
\text { planning method }\end{array}$ & $\begin{array}{l}\text { Contraceptive } \\
\text { knowledge (\%) }\end{array}$ & $\begin{array}{l}\text { Ever use of } \\
\text { contraceptive (\%) }\end{array}$ \\
\hline Any method & 99 & 41.4 \\
\hline $\begin{array}{l}\text { PP intrauterine } \\
\text { contraceptive device }\end{array}$ & 5 & 1 \\
\hline Female sterilization & 98.2 & 3 \\
\hline OCP/minipill & 79.5 & 3 \\
\hline Condom & 71 & 12 \\
\hline $\begin{array}{l}\text { Intrauterine contraceptive } \\
\text { device }\end{array}$ & 70.6 & 2.6 \\
\hline Male sterilization & 89.3 & 0 \\
\hline $\begin{array}{l}\text { Lactational amenorrhea } \\
\text { method }\end{array}$ & 56.7 & 8 \\
\hline Natural methods & 48.9 & 11.8 \\
\hline
\end{tabular}

- Calls them on an appropriate date for PNC and newborn checkup and care and immunization of the baby and giving them iron/folic acid and calcium tablets.

If client has already adopted a PPFP method, then solves telephonically any problem related to it, gives them a date for follow-up at the health facility, and explains the importance of its consistent usage.

The counselor made the following free phone calls to the potential clients:

First call within 3 to 7 days of delivery

Second call in 20 to 42 days of delivery

Third call in 42 to 60 days of delivery.

The counselor made the following free phone calls to the potential clients:

First call within 3 to 7 days of delivery

Second call in 20 to 42 days of delivery

Third call in 42 to 60 days of delivery

This tracking started in 2013 and completed in 2016.

The results of acceptability and acceptance are shown in Tables 2 to 4.

\section{RESULTS}

- This pilot study has shown very promising results. Hence, according to this study, the effective PPFP has increased to $29.7 \%$, which was initially $4.9 \%$

- The PPFP acceptance has increased from 6\% in 2012 to $73 \%$ in 2015, including all methods (condom and OCP/POP also) (Graphs 1 and 2)

- The PP women who did not accept any method were referred to their respective NGO and they were then counseled by them, and the acceptance further increased by another $5 \%$

- Moreover, PPIUCD has emerged as an alternative to female sterilization as it is reversible, safe, and longacting method of contraception
Table 3: Postpartum use of effective contraceptive method in women delivered at S.N. Medical College, Agra

\begin{tabular}{|c|c|c|c|c|}
\hline $\begin{array}{l}\text { Postpartum use of effective } \\
\text { contraception }\end{array}$ & 2012 & 2013 & 2014 & 2015 \\
\hline Number of total deliveries & 2,090 & 1,828 & 2,020 & 2,227 \\
\hline $\begin{array}{l}\text { Number of PP women } \\
\text { counselled for PPFP }\end{array}$ & 820 & 1,080 & 1,600 & 2,000 \\
\hline $\begin{array}{l}\text { Number of PP women accepting } \\
\text { a method (all PPFP methods) }\end{array}$ & 112 & 800 & 1,400 & 1,600 \\
\hline $\begin{array}{l}\text { Frequency of effective } \\
\text { contraceptive method at } \\
\text { hospital discharge (PPIUCD + } \\
\text { sterilization) }\end{array}$ & 90 & 338 & 512 & 594 \\
\hline $\begin{array}{l}\text { Percentage of effective } \\
\text { acceptance }\end{array}$ & 4.30 & 18.49 & 25.34 & 29.70 \\
\hline
\end{tabular}

Table 4: Acceptance of individual PPFP method by women delivered at S.N. Medical College, Agra

\begin{tabular}{lllll}
\hline Postpartum contraceptive method & 2012 & 2013 & 2014 & 2015 \\
\hline PPIUCD & 36 & 286 & 454 & 486 \\
Female sterilization & 54 & 52 & 58 & 108 \\
Lactational amenorrhea method & 2 & 150 & 300 & 350 \\
OCP/minipill & 2 & 12 & 18 & 20 \\
$\begin{array}{l}\text { Depot medroxyprogesterone } \\
\text { acetate }\end{array}$ & 4 & 50 & 70 & 86 \\
Condom & & & & \\
No method & 14 & 250 & 500 & 550 \\
\hline
\end{tabular}

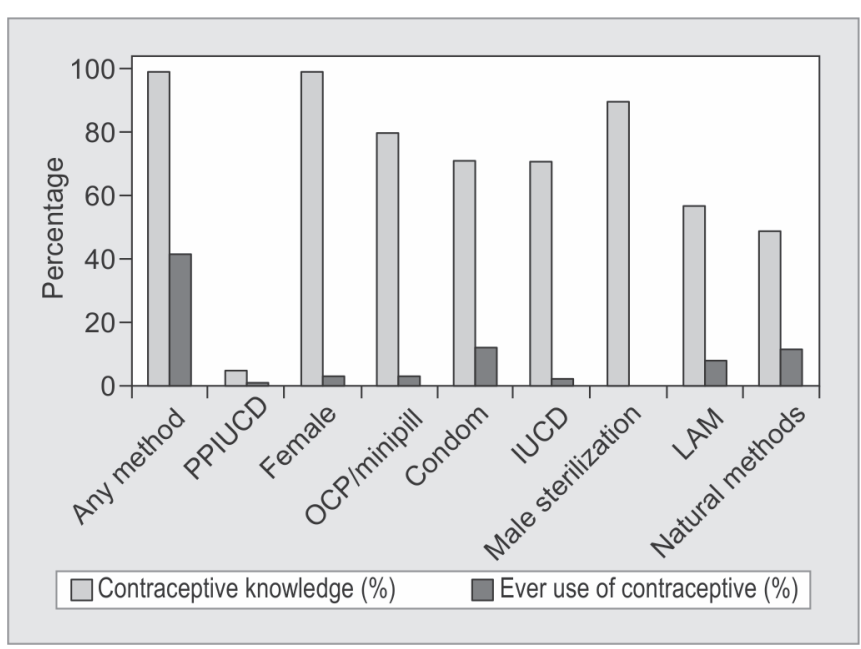

Graph 1: Contraceptive scenario among postpartum women delivered at S.N. Medical College, Agra

- From the tables, it is evident that PPIUCD in 2012 was $1.7 \%$ and in 2015 it has increased to $21.8 \%$

- The increase seems to be due to awareness among the urban poor population about PPIUCD and trainings conducted for the service providers.

\section{CONCLUSION}

The clients are gaining confidence and faith in the counselor and telephone her for even small things and health-related issues of mothers or babies and are able 


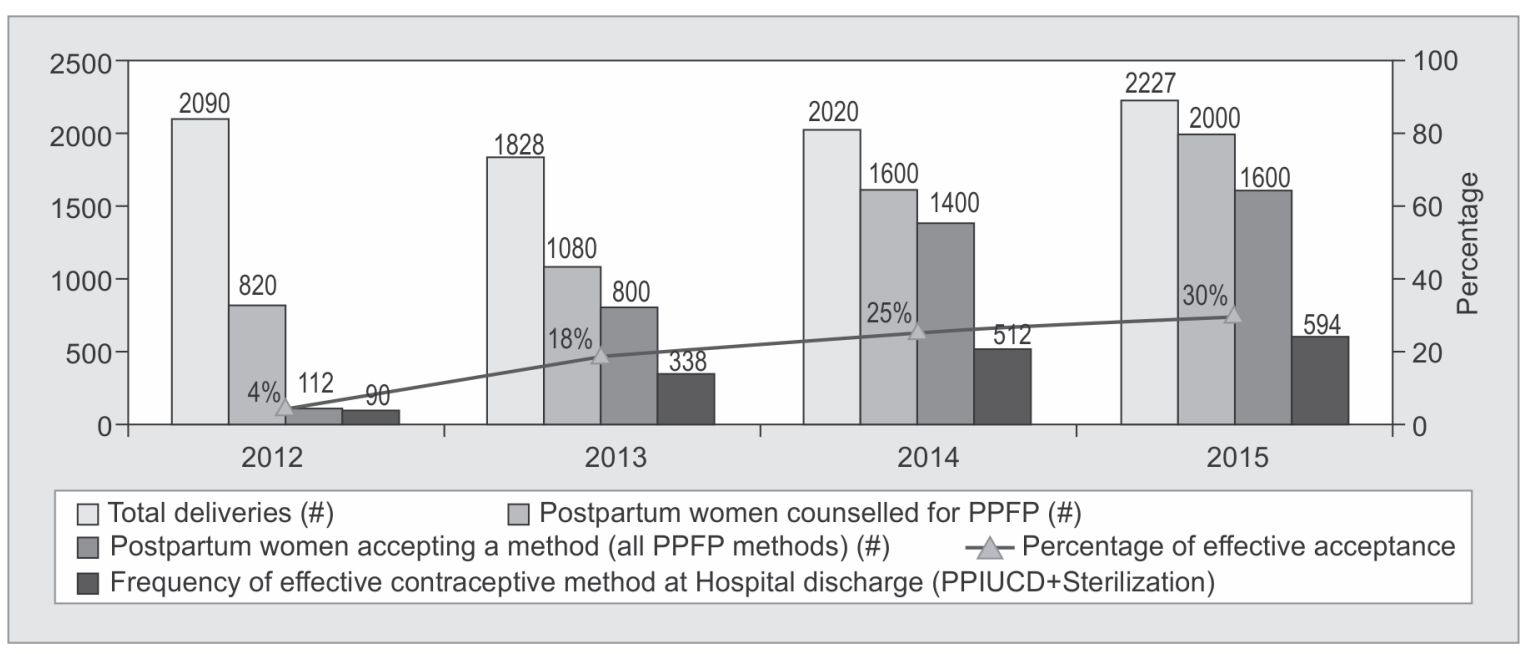

Graph 2: Postpartum use of effective contraceptive method in women delivered at S.N. Medical College, Agra

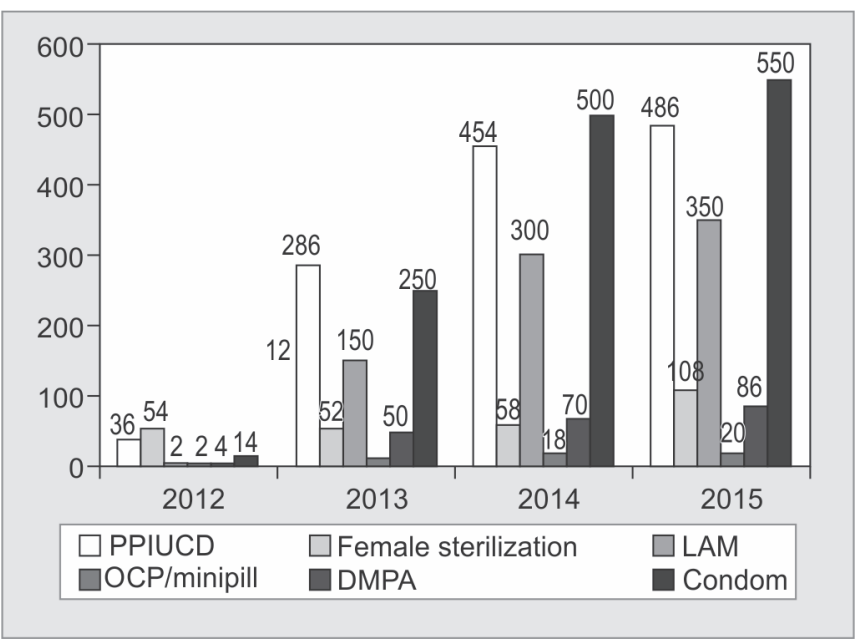

Graph 3: Acceptance of individual postpartum family planning method by women delivered at S.N. Medical College, Agra

to communicate and connect with her as a health guide and helper at the facility.

The acceptance of PPFP is increasing and is on the rise as the client can make an informed choice by choosing a method, provider, and facility of his/her choice for spacing, or limiting their family according to the couple's contraceptive needs through effective counseling by the counselor, which is again reinforced by the NGO workers working in that particular basti and the client gets satisfied fully for adoption of PPFP methods and services as all the myths and misconceptions are removed and dispelled (Graphs 3 and 4).

Some of the clients are themselves demanding PPFP (immediate) methods and services as awareness has increased and they have been thoroughly counseled during the ANC period and have had time to ponder over spacing or limiting their family size and adopting a particular PPFP method of their liking and choice.

The most likeable and desirable PPFP method is PPIUCD.
mHealth services are cost-effective and have the potential to reach youth, urban slums, and rural population where geographical distances or daily wages earning loss restrict access to in-person services.

\section{CHALLENGES}

- Many of the clients do not have mobile phones as they are very poor and cannot afford one

- Most of the mobile numbers given and registered with the counselor are of their husbands who are at their workplaces during the daytime and direct communication with the delivered client is not possible

- Some of the husbands do not allow their wives to talk directly on phone with the counselor. They ask the counselor to talk to them

- Sometimes the counselor has to make phone calls at odd timings (7-9 pm), when the husband will reach home after work and give the mobile to wife to talk over with the counselor, which makes the things difficult and hinders our achievement.

\section{FUTURE STEPS}

To bring about a sustainable change and good output in PPFP, a refresher training should be conducted every 6 months for the counselors and NGO staff on PPFP, including how to handle and deal with the various odds and situations arising in the PP period related to maternal and child health.

\section{LEARNING}

Yes, to start with, it's a good step and initiative to improve and increase acceptance of PPFP methods and services for the urban poor.

For sustainability the work of telephonic tracking should be assigned to a call center who can do it on a large scale through experienced counselors round the clock and 

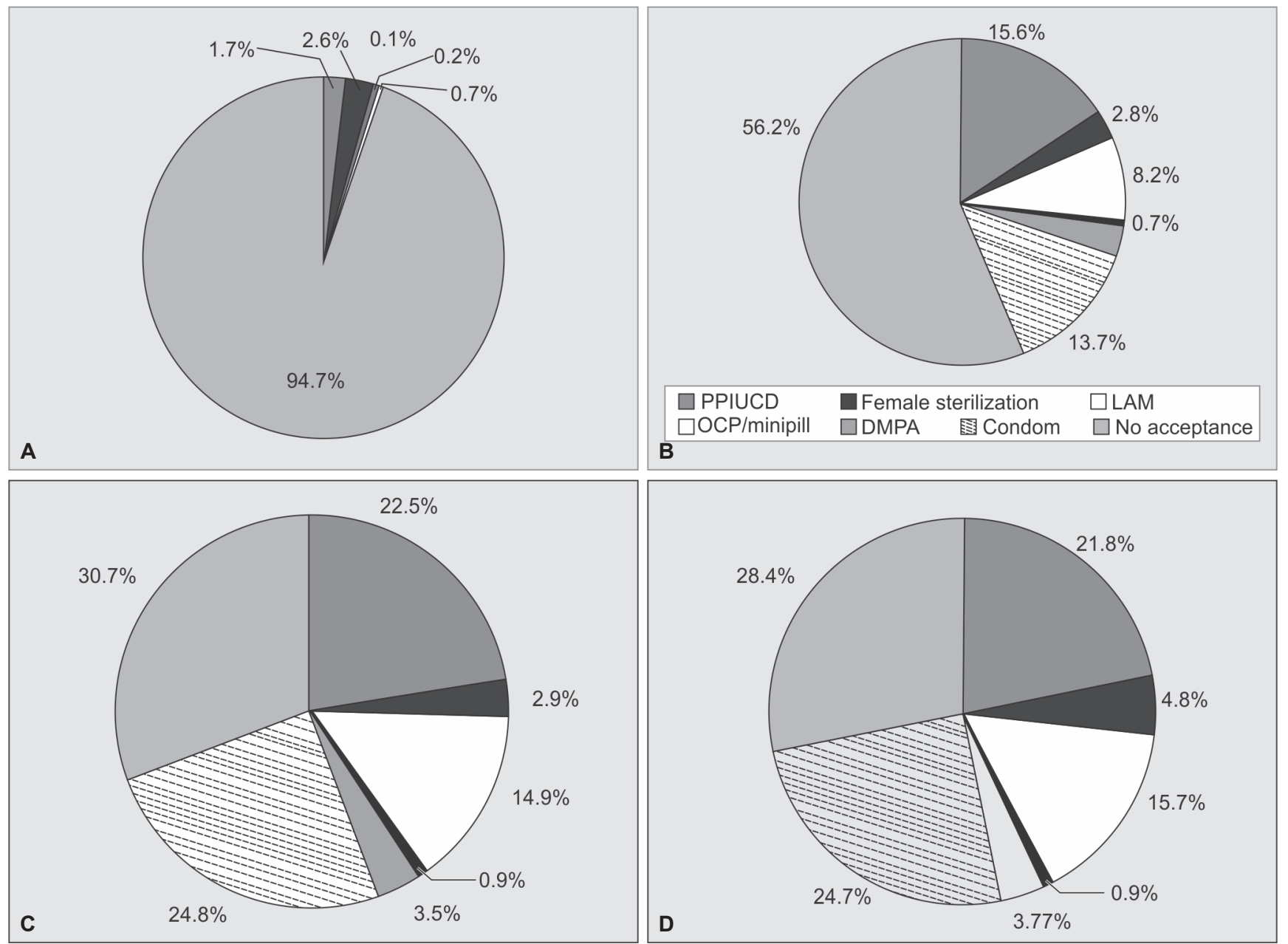

Graphs 4A to D: Acceptance of individual postpartum family planning method by women delivered at S.N. Medical College, Agra-2012-2015

covering all the urban slums of Agra city instead of only a limited number of bastis catered to by the S.N. Medical College and hospital.

All efforts should be done to convince the government and carry this activity forward through government counselors.

Mobile tracking for quality PPFP services is a boon for PP women.

This innovation should be used as a role model to cover the whole of India.

\section{ACKNOWLEDGMENT}

Authors would like to thank the Urban Health Initiative for supporting and providing a dedicated counselor for tracking the PP women through mobile phone.

\section{REFERENCES}

1. World Health Organization (WHO). Report of a technical consultation on birth spacing. Geneva, Switzerland: WHO; 2005.

2. World Health Organization (WHO). Programming strategies for post-partum family planning. Geneva, Switzerland: WHO; 2013.
3. Borda M. Family planning needs during the extended postpartum period in India (internet). Access family planning initiative brief 2009 (accessed 12 march 2015).

4. National Family Health Survey (NFHS-3) 2005-06, vol. 1. IIPS (International Institute for Population Sciences), Mumbai, India; 2007.

5. Ross JA, Winfrey WL. Contraceptive use, intention to use and unmet need during the extended postpartum period. Int Fam Plan Perspect 2001 Mar;27(1):20-27.

6. District Level Household and Facility Survey (DLHS-3) 2007-08. IIPS (International Institute of Population Sciences), Mumbai, India; 2010.

7. Grimes DA, Lopez LM, Schulz KF, Van Vliet HA, Stanwood NL. Immediate post-partum insertion of intrauterine devices. In: The Cochrane collaboration, editor. Cochrane Database Syst Rev (Internet). Chichester: John Wiley \& Sons Ltd; 2010.

8. Kumar S, Sethi R, Balasubramaniam S, Charurat E, Lalchandani K, Semba R, Sood B. Women's experience with postpartum intrauterine contraceptive device use in India. Reprod Health 2014 Apr;11:32.

9. Patnaik UK, Mishra TK. User satisfaction and retention of $\mathrm{Cu}-\mathrm{T}$ (IUD) amongst rural women in Orissa. Health Popul Perspect 2003;26(2):52-58.

10. Performance of key HMIS indicators for all India, financial year. 2014-15, Ministry of Health \& Family Welfare, Government of India Health Management information system (HMIS) portal 2014-2015. 
11. National Health Portal Ministry of Health and Family Welfare, New Delhi 2014, Janani Suraksha Yojana (accessed 12 March 2015).

12. MichaelP, Batavia H,Kaonga N, SearleS, KwanA, Goldberger A, $\mathrm{Fu}$ L, Ossman J. Barriers and gaps affecting mHealth in low and middle income countries policy white paper. Center For Global Health and Economic Development, Earth Institute, Columbia, USA; 2010 May.

13. Kallander K, Tibenderana J, Akpoghenta O, Strachen D, Hill Z, ten Asbroek A, Conteh L, Kirkwood BR, Meek SR. Mobile health approaches and lessons for increased performance and retention of community health workers in low and middle income countries: a review. J Med Internet Res 2013 Jan;15(1):e17.

14. Free C, Phillips G, Galli L, Watson L, Felix L, Edwards P, Patel V, Haines A. The effectiveness of mobile-health technologybased health behavior change or disease management interventions, for health care consumers: a systematic review. PLoS Med 2013;10(1):e1001362.

15. Tripney J, Kwan L, Bird K. Postabortion family planning counseling and services for women in low-income countries: a systematic review. Contraception 2013 Jan;87(1):17-25.

16. Hou M, Hurwitz S, Kavanagh E, Fortin J, Goldberg A. Using daily text message reminders to improve adherence with oral contraceptives: a randomized controlled trial. Obstet Gynecol 2010 Sep;116(3):633-640.

17. Castano P, Bynum J, Andres R, Lara M, Westhoff C, Effect of daily text message on oral contraceptive continuation, a randomized controlled trial. Obstet Gynecol 2012;119(1): 14-20.

18. Lengle K, Vahdat H, Ndakidemi E, Lasway C, Zan T. evaluating feasibility, reach and potential impact of a text message family planning information service in Tanzania. Contraception 2013 Feb;87(2):251-256.

19. Smith C, Vannak U, Sokhey L, Ngo TD, Gold J, Khut K, Edwards P, Rathavy T, Free C. Mobile Technology for Improved Family Planning Services (MOTIF): study protocol for a randomized controlled trial. Trials 2013 Dec;14:427.

20. Smith C, Ngo TD, Gold J, Edwards P, Vannak U, Sokhey L, Machiyama K, Slaymaker E, Warnock R, McCarthy O, et al. Effect of a mobile phone-based intervention on post-abortion contraception: a randomized controlled trial in Cambodia. Bull World Health Organ 2015 Dec;93(12):842-850A.

21. Smith C, Vannak UK, Sokhey L, Ngo TD, Gold J, Free C. Mobile Technology for Improved Family Planning (MOTIF): the development of a mobile phone-based (m-Health) intervention to support post-abortion family planning (PAFP) in Cambodia. Reprod Health 2016;13:1. 